\title{
Flavobacterium psychrophilum y su patología en alevines de Onchorhynchus mykiss del centro piscícola EI Ingenio, Huancayo
}

\author{
Flavobacterium psychrophilum and its pathology in alevins of Onchorhynchus \\ mykiss from the El Ingenio fish farm, Huancayo
}

\author{
Jorge León ${ }^{1}$, Rita Ávalos ${ }^{1}$ y Milagros Ponce ${ }^{2}$
}

\begin{abstract}
1 Laboratorio de Ecología Microbiana, Instituto de Ciencias Biológicas Antonio Raimondi (ICBAR), Facultad de Ciencias Biológicas, Universidad Nacional Mayorde San . . , Perú. Email Jorge León: jleonq@unmsm.edu.pe

2 Laboratorio de Microbiología, Centro Piscícola El Ingenio, Huancayo, Perú
\end{abstract}

Presentado: $19 / 05 / 2008$ Aceptado: $17 / 07 / 2008$ Publicado online: $26 / 02 / 2009$

\begin{abstract}
Resumen
En el presente trabajo se reporta la presencia de Flavobacterium psychrophilum, como agente causante de la patología "enfermedad bacteriana del agua fría" en alevines de Onchorhynchus mykiss "trucha arco iris" del Centro Piscícola El Ingenio, Junín (3250 m de altitud). La lesión macroscópica externa más frecuente fue la ulceración profunda de la región dorsal del pez acompañado de un ennegrecimiento localizado de la piel. Internamente se observó una marcada esplenomegalia, palidez del hígado, riñón y branquias, inflamación del intestino y acumulación de líquido ascítico en el peritoneo. No se detectó hemorragia interna. En Agar Cytophaga Modificado (ACM) según Anaker \& Ordal (1959) fueron aisladas inicialmente 29 Gram negativas, de las cuales según la caracterización fenotípica y pruebas bioquímicas 9 fueron consideradas como $F$. psychrophilum. Pruebas de susceptibilidad antibiótica mostraron alta sensibilidad de las cepas a Gentamicina, Ceftazidina, oxitetraciclina, Norfloxacina, furazolidona, Ciprofloxacina y Cefoxitina.
\end{abstract}

Palabras clave: Flavobacterium, Flexibacter, Enfermedad Bacteriana del Agua Fría, trucha arcoiris.

\section{Abstract}

The present paper reports the presence of Flavobacterium psychrophilum such as pathological agent of "bacterial disease of cold water" on juvenile Onchorhynchus mykiss "rainbow trout" from El Ingenio fish farm, Junín $(3250 \mathrm{~m})$. The ulceration of the dorsal area was the most frequent macroscopic external injury as well the localized blackening of the skin. Internally there was a marked splenomegaly, pallor of the liver, kidney and gills, inflammation of the intestine and ascitic fluid in the peritoneum. Internal hemorrhage was not detected. 29 strain Gram negative were isolated in Modified Cytophaga Agar (MCA) (Anaker \& Ordal, 1959), which according to the phenotypic characterization and the biochemical tests 9 were considered as F. psychrophilum. Tests of antibiotic susceptibility showed high sensitivity of this strains to Gentamicin, Ceftazidine, oxytetracycline, Norfloxacine, furazolidone, Ciprofloxacine and Cefoxitine.

Keywords: Flavobacterium, Flexibacter, Cold Water Bacterial Disease, rainbow trout.

\section{Introducción}

El rápido desarrollo de la acuicultura y del intercambio internacional de animales acuáticos cultivables ha traído como consecuencia el progresivo crecimiento de los problemas patológicos, que a su vez ocasionan bajas de rendimiento y considerables pérdidas económicas en muchos países dedicados a esta actividad (Cuéllar 1984).

Las patologías de origen bacteriano representan un riesgo importante en el desarrollo de la acuicultura continental (Padrós y Furones 2002). Las bacterias Gram negativas son las principales causantes de enfermedades en los salmónidos; siendo el grupo de las flavobacterias responsables de cuadros patológicos habituales que afectan la piel, aletas y branquias y son conocidas como la "enfermedad bacteriana de la branquia" o "enfermedad de la columnaris"; pero en algunos casos como las infecciones por Flavobacterium psychrophilum (antes Flexibacter psychrophilus o Cytophaga psychrophila) (Bernardet et al. 1996) pueden llegar a producir además serios procesos septicémicos (Padrós y Furones, 2002). Flavobacterium psychrophilum es un bacilo Gram negativo que origina diversas patologías en peces salmónidos, desde necrosis ulcerativa de la piel hasta una infección sistémica (Holt et al. 1993). Ésta patología ha recibido diferentes denominaciones: "enfermedad del pedúnculo", "enfermedad del agua fría” (CWD) (Borg, 1960), "enfermedad bacteriana del agua fría” (BCWD) (Holt et al. 1993) y el "síndrome del alevín de la trucha" (RTFS) (Rangdale et al., 1996). La "enfermedad bacteriana del agua fría" ha sido detectada en la mayoría de las especies de salmónidos en cultivo (Amos 1985; Dalsgaard 1993; Austin \& Austin 1993). Flavobacterium psychrophilum ha sido descrito como el agente causal de la "enfermedad o Síndrome del alevin de la trucha arco iris” (Crump et al. 2001). Inicialmente, se consideró que esta enfermedad se restringía al norte del continente americano, pero desde finales de la década de los años 80 se sabe que tiene una distribución mundial que abarca Alemania (Weis 1987), Francia (Bernardet et al., 1988), Dinamarca (Dalsgaard \& Horlyck 1990), Reino Unido (Santos et al. 1992), España (Toranzo \& Barja 1993), Finlandia (Wiklund et al. 1994), Australia (Smitchke \& Carson 1995), Japón (Wakabayashi et al. 1991) y Chile (Bustos et al. 1995). En la actualidad es probable que la bacteria esté ampliamente diseminada a través del mundo (Ekman, 2003; Cipriano \& Holt 2005).

En nuestro medio no existe literatura científica que describa casos de la "enfermedad bacteriana del agua fría" o "Síndrome del alevín de trucha arco iris". El presente estudio describe la patología de ésta enfermedad y las características de Flavobacterium psychrophilum procedentes de un brote atípico que apareció entre los meses de junio, julio y agosto del ańo 2003, afectando alevines de trucha arco iris (Oncorhynchus mykiss) en el Centro Piscícola El Ingenio - Huancayo.

\section{Material y métodos}

\section{Muestreo}

Fueron seleccionados 14 alevinos enfermos de trucha arcoiris de 5 a $7 \mathrm{~cm}$ de longitud provenientes de los estanques de cultivo de la piscigranja El Ingenio, Huancayo (Región Junín) (3250 m de altitud). Paralelamente, muestras de agua fueron tomadas de los estanques que contenían los especimenes afectados. Asimismo, se determinaron la temperatura y $\mathrm{pH}$ del agua. A manera de control se tomaron peces de apariencia sana. 


\section{Procesamiento y aislamiento de flavobacterias}

Las muestras fueron procesadas en el laboratorio de la piscigranja. Con el fin de aislar al patógeno se realizaron disecciones asépticas de los peces para obtener muestras de líquido ascítico del peritoneo, forúnculos, raspado de las ulceraciones cutáneas, maceración de órganos internos (bazo, hígado, riñón) y agallas; las cuales fueron sembradas en el Agar Cytophaga Modificado según Anaker \& Ordal (AOA) (1959) (triptona 0,5\%; acetato de sodio $0,02 \%$; extracto de levadura $0,05 \%$, extracto de carne $0,05 \%$ y agar $1,5 \%$ ) y Agar Tripticasa Soya (TSA). Paralelamente se prepararon láminas para la observación directa en "gota pendiente" y frotis para la coloración Gram. Las muestras controles (peces sanos) y las muestras de agua, también fueron procesadas bajo las mismas condiciones. Los cultivos fueron incubados a $20{ }^{\circ} \mathrm{C}$ por 48 a 96 horas.

\section{Pruebas de identificación}

Las pruebas fueron realizadas en el Laboratorio de Microbiología Ambiental y Biotecnología de la Facultad de Ciencias Biológicas de la Universidad Nacional Mayor de San Marcos, Lima. Las lecturas presuntivas se realizaron a partir de cultivos de 48 h de incubación y consistieron en la observación directa de cultivos en "gota pendiente" acompañadas de coloración Gram, y pruebas bioquímicas preliminares según las recomendaciones de Skarmeta (1996). Para la identificación preliminar se seleccionaron colonias del medio AOA y TSA con características similares tanto de morfología como de coloración Gram. La identificación final de las Gram negativas se realizó siguiendo la metodología convencional según Austin \& Austin (1993); y para el caso particular de las flavobacterias se tomó en cuenta además la metodología señalada por Cipriano et al. (1996) y Shotts \& Starliper (1999).

\section{Susceptibilidad in vitro a diversos antimicrobianos}

Las cepas aisladas de alevines con patología de ulceración de la piel y órganos internos afectados, previa coloración Gram fueron sometidos a pruebas de sensibilidad in vitro frente a diversos antimicrobianos mediante la técnica de Kirby-Bauer, según recomendaciones del National Committee for Clinical Laboratory Standards (NCCLS, 1991). A partir de colonias de 48-72 horas, se preparó una suspensión con una concentración equivalente al tubo $0,5 \mathrm{McF}$ arland $\left(1,5 \times 10^{8} \mathrm{ufc} / \mathrm{ml}\right)$ y se sembró mediante una tórula en TSA y AOA. Se utilizaron sensidiscos con los antimicrobianos: bacitracina $(10 \mu \mathrm{g})$, norfloxacino (10 $\mu \mathrm{g})$, ciprofloxacino $(5 \mu \mathrm{g})$, ampicilina $(10 \mu \mathrm{g})$, cefoxitina $(30$ $\mu \mathrm{g})$, clindamicina $(2 \mu \mathrm{g})$, ácido nalidixico $(30 \mu \mathrm{g})$, penicilina $(10 \mathrm{U})$, gentamicina $(10 \mu \mathrm{g})$, ceftazidina $(30 \mu \mathrm{g})$, furazolidona $(100 \mu \mathrm{g})$, oxitetraciclina $(30 \mu \mathrm{g})$ y sulfatrimetoprim $(25 \mu \mathrm{g})$. Se incubaron por 5 días a $20^{\circ} \mathrm{C}$.

\section{Resultados y discusión}

\section{Signos anátomo-patológicos}

Los especimenes enfermos (14) de alevines de "trucha arcoiris" (5-7 $\mathrm{cm}$ de longitud y $25 \mathrm{~g}$ de peso promedio) analizados en este estudio presentaban macroscópicamente cuadros patológicos muy evidentes de erosiones o ulceraciones severas y muy profundas que afectaban la piel, músculo, aleta dorsal y región del pedúnculo caudal del huésped a manera de "silla de montar" (Fig. 1a). En general, los alevines afectados se mostraron con un cuadro de lesiones propias de una infección aguda o sub-aguda, siendo común la observación de lesiones macroscópicas evidentes y frecuentes como el ennegrecimiento local de la piel, distensión abdominal y ocasionalmente exoftalmia (Fig. 1b).

Otras características adicionales fueron la letargia, la inapetencia, natación errática y/o permanencia casi siempre aislado cerca de la salida del agua. La Figura 2 muestra los signos clínicos más relevantes que afectan a los órganos internos como: esplenomegalia, palidez del hígado, riñón y branquias; inflamación del intestino y acumulación del líquido ascítico en el peritoneo. No se detectó hemorragias externas ni internas.

En preparaciones frescas y coloreadas procedentes de úlceras se observaron bacilos finos en disposición de "empalizada" (Fig. 3a) o filamentosas (Fig. 3b) con motilidad presuntamente deslizante. En otros casos, no se detectó motilidad aparente.

Los signos clínicos de la flavobacteriosis en salmónidos así como la mortalidad dependen del tamańo de los peces afectados. Sin embargo, Flavobacterium psychrophilum se caracteriza por causar infecciones agudas principalmente en alevinos, caracterizados por una marcada erosión dorsal y/o peduncular acompańada de una pigmentación oscura, además por causar mortandad hasta 50\% de la población afectada (Holt et al. 1993).

Según el cuadro patológico y las características fenotípicas de las 9 cepas evaluadas en este estudio, observamos gran similitud con el "síndrome del alevín de trucha arcoiris" causado por Flavobacterium psychrophilum causante de la enfermedad bacteriana del agua fría ("Bacterial Cold Water Disease" o BCWD). Este cuadro patológico fue descrito por primera vez en alevines de trucha arco iris (O. mykiss) en Estados Unidos (Davis 1946) con el nombre de enfermedad del pedúnculo. La enfermedad fue posteriormente descrita en alevines de salmón coho (O. kisuth) por Borg (1960), quien la denominó como enfermedad de baja temperatura o enfermedad bacteriana del agua fría y propuso a Cytophaga psychrophila como el agente causal. En los últimos 20 años han sido descritas en diferentes partes del mundo patologías similares en alevinos, juveniles y adultos de "trucha arcoiris", todas bajo el nombre genérico de síndrome del alevin de trucha arcoiris ("Raibow Trout Fry Sindrome" o RTFS) (Bernardet et al. 1988; Sarti et al. 1992; Toranzo \& Barja 1993; Bustos et al. 1995; Ostland et al. 1999; Madetoja et al. 2001; Lorenzen et al. 1991; Wakabayashi et al. 1991; Wiklund et al. 1994; Rangdale 1999; Nematollahi et al. 2003).

Flavobacterium psychrophilum ha sido aislada también en peces no salmónidos (Amita et al. 2000; Madetoja et al. 2002), sin embargo en todos los casos, el agente etiológico presentaba características similares a las descritas por Borg (1960) siendo denominado primero como Cytophaga psychrophila, luego como Flexibacter psychrophilus y actualmente Flavobacterium psychrophilum (Cipriano \& Holt 2005).

En un cuadro de infección externa o sistémica el patógeno principal generalmente es asociado con otras bacterias principalmente Gram negativas como Yersinia, Edwarsiella, Pseudomonas, Aeromonas y otros (Padrós y Furones 2002).

\section{Características de cultivo bacteriano y pruebas bioquími- cas de identificación}

A partir de las muestras patológicas se lograron aislar tanto del medio AOA como del TSA un total de 29 cepas Gram negativas, las cuales mostraron características de colonia algo similares 


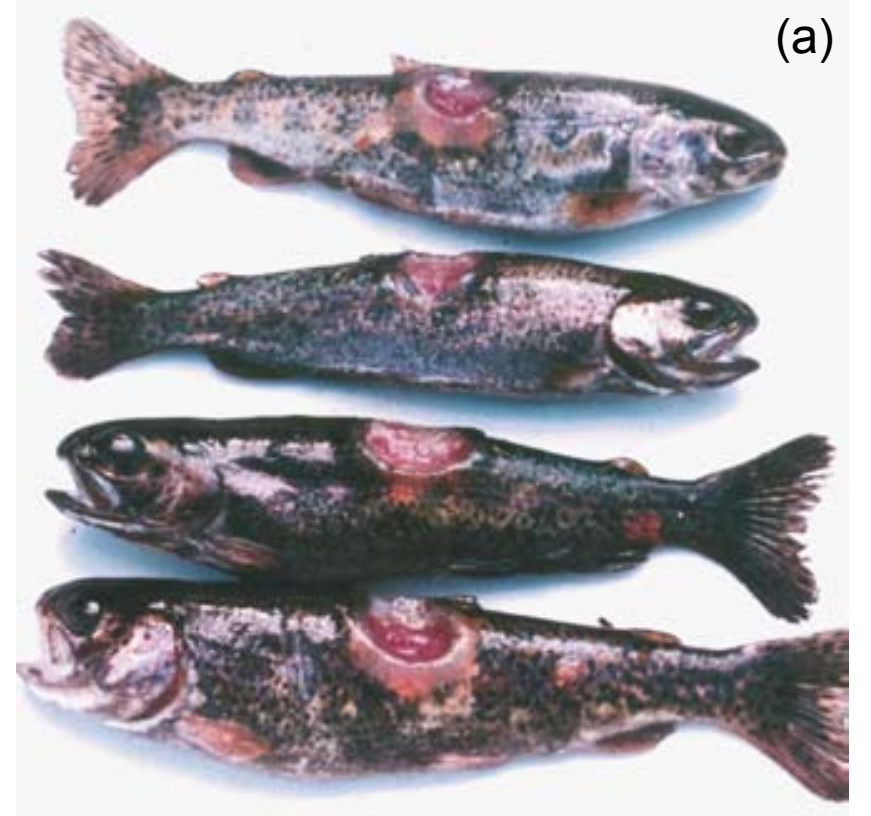

(b)

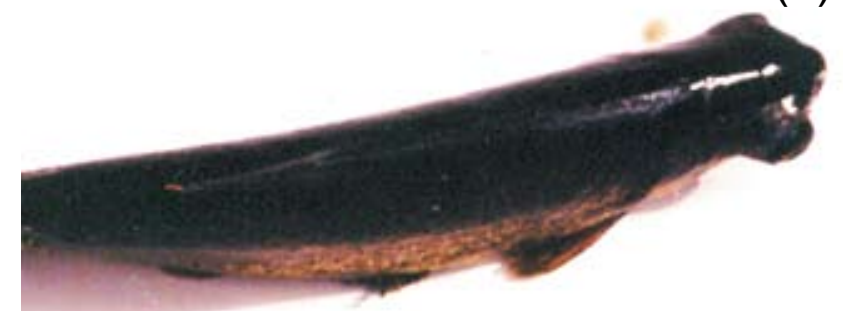

Figura 1. Cuadro característico de la "Enfermedad Bacteriana de Agua Fría" o "Síndrome del Alevín de Trucha Arco Iris" en Onchorhynchus mykiis (a); ocasionalmente se observa casos de pigmentación de la piel y exoftalmia (b).

(Tabla 1). Dichas colonias presentaron un tamaño comprendido entre 1 a $4 \mathrm{~mm}$ de diámetro, circulares, lisas, borde entero $\mathrm{u}$ ondulado, aplanadas o poco elevadas, translúcidas, la mayoría no pigmentadas o de escasa pigmentación y algunas adheridas al medio. Se tomaron en cuenta mayormente las colonias pro-

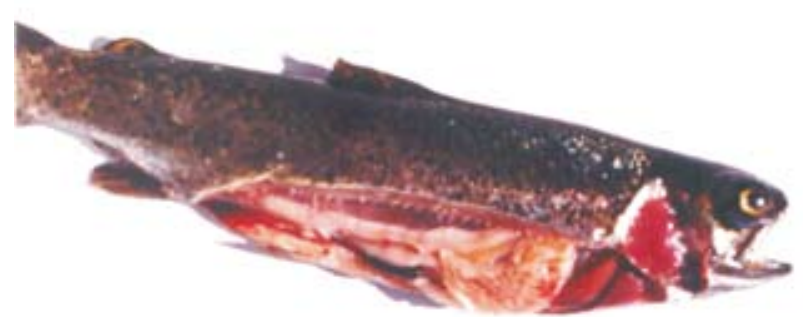

Figura 2. Signos clínicos: : esplenomegalia, palidez del hígado, riñón y branquias; inflamación del intestino y acumulación del líquido ascítico en el peritoneo. observados a nivel de órganos internos en un espécimen juvenil de "trucha arco iris" causados por Flavobacterium psychrophilum.

venientes del medio AOA, debido a que TSA por ser un medio muy enriquecido permitió crecimiento de colonias morfológicamente variables. Microscópicamente, resultaron ser todos Gram negativos, bacilos finos o bastoncillos delgados rígidos, algunos filamentosos (Fig. 3c). La motilidad de las bacterias, determinada a partir de colonias y caldos de crecimiento mediante la técnica de "gota pendiente", mostró resultados heterogéneos. En 9 casos se confirmó la motilidad deslizante y en otras ocasiones dicho carácter se mostró muy discreto o de tipo flagelar al igual que otros Gram negativos. Entre otras características preliminares las reacciones de oxidasa y catalasa resultaron positivas en todos los casos, con excepción de las cepas 11 y 16 que resultaron catalasa negativas (Tabla 1). A partir de las muestras de agua procesadas no se lograron aislar colonias presuntivas de flavobacterias.

Los signos externos de la enfermedad no tienen gran valor para diagnosticar al patógeno Flavobacterium psychrophilum, porqué son similares a los observados en peces afectados por otras enfermedades como la "columnaria" (bacteriana) y la Necrosis Pancreática Infecciosa (viral). Sin embargo el examen microscópico de muestras de úlceras y órganos internos afectados como el riñón y el hígado permiten una buena identificación preliminar al observar células bacterianas filamentosas (Austin \& Austin, 1993; Fig. 3b).

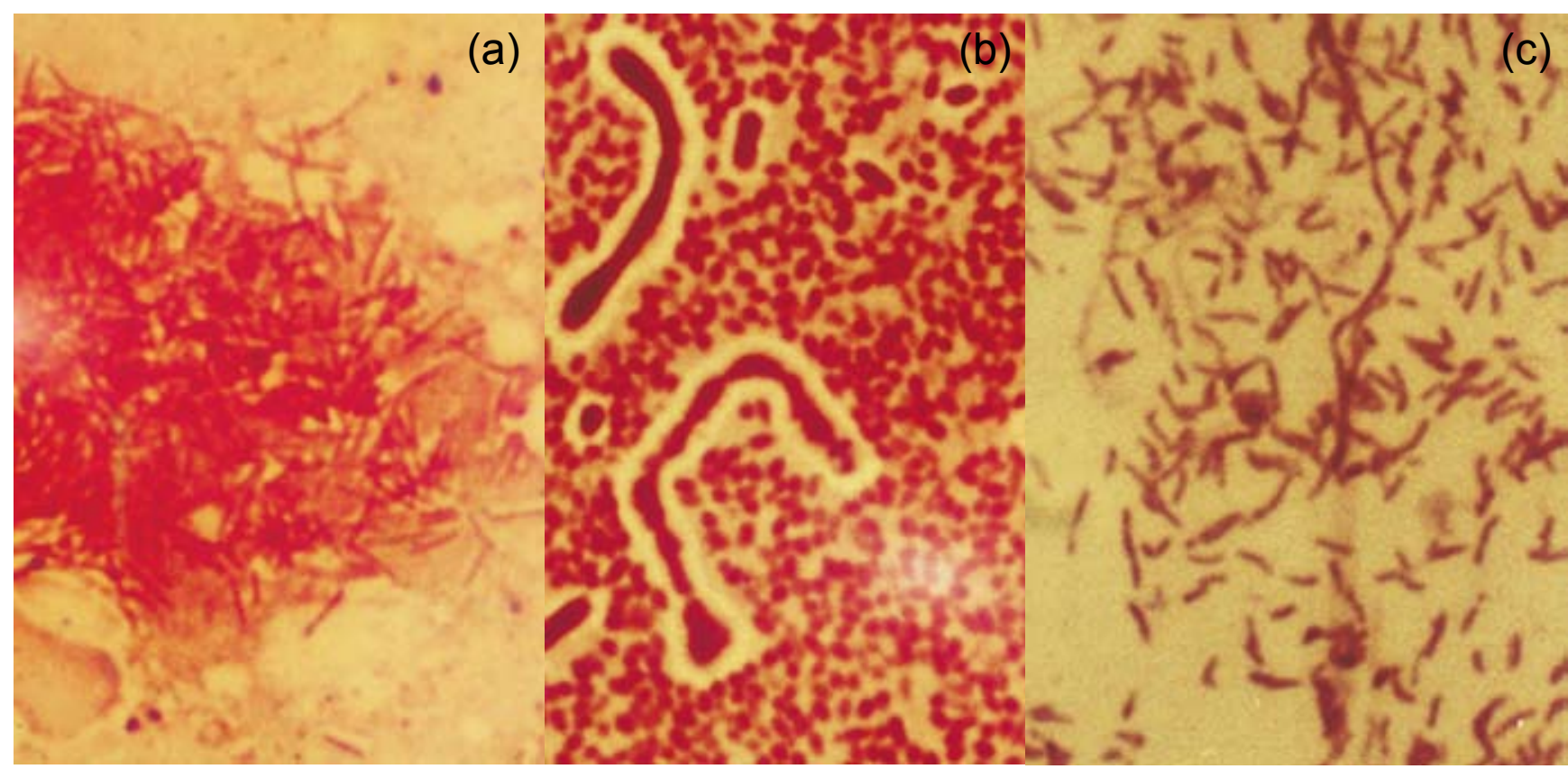

Figura 3. Observación microscópica de flavobacterias: coloración Gram de un frotis directo de una úlcera cutánea (a); frotis de un órgano interno afectado (b); Gram a partir de una colonia en el medio AOA (c). 
Tabla 1. Origen y características primarias de 29 cepas de bacterias aisladas de alevines enfermos de Oncorhynchus mykiss "trucha arco iris", Centro Piscícola El Ingenio, Huancayo, 2003. En negrita: cepas identificadas como Flavobacterium psychrophilum.

\begin{tabular}{|c|c|c|c|c|c|c|c|}
\hline Cepa & Fuente de aislam..$\left.^{*}\right)$ & Estanque & Gram & Motilidad (**) & Oxidasa & Catalasa & Características de colonia $\left({ }^{* * *}\right)$ \\
\hline 1 & $\mathrm{H}$ & 1 & - & $\mathrm{F}$ & + & + & Mucoide, circular, SP \\
\hline 2 & $\mathrm{H}$ & 1 & - & $\mathrm{F}$ & + & + & Mucoide, circular, SP \\
\hline 3 & $\mathrm{H}$ & 1 & - & $\mathrm{F}$ & + & + & Mucoide, circular, SP \\
\hline 4 & UE & 7 & - & $\mathrm{F}$ & + & + & Lisa, aplanada, SP \\
\hline 5 & UE & 7 & - & $\mathrm{F}$ & + & + & Lisa, aplanada, SP \\
\hline 6 & UE & 8 & - & $\mathrm{F}$ & + & + & Mucoide, grisáceo \\
\hline 7 & UE & 8 & - & $\mathrm{F}$ & + & + & Mucoide, grisáceo \\
\hline 8 & UE & 20 & - & $\mathbf{D}$ & + & + & Mucoide, convexo, AT \\
\hline 9 & $\mathrm{R}$ & 20 & - & I & + & + & Mucoide, circular, SP \\
\hline 10 & $\mathbf{R}$ & 28 & - & PD & + & + & Lisa, aplanada, NT \\
\hline 11 & $\mathbf{R}$ & 28 & - & PD & + & - & Lisa, aplanada, NT \\
\hline 12 & UE & 28 & - & I & + & + & Mucoide, lisa, incolora \\
\hline 13 & UE & 28 & - & D & + & + & Mucoide, lisa, PN \\
\hline 14 & $\mathrm{H}$ & 7 & - & $\mathrm{F}$ & + & + & Mucoide, aplanada, SP \\
\hline 15 & $\mathrm{H}$ & 7 & - & F & + & + & Mucoide, lisa, SP \\
\hline 16 & UE & 1 & - & I & + & - & Lisa, aplanada, SP \\
\hline 17 & UE & 1 & - & I & + & + & Mucoide, lisa, incolora \\
\hline 18 & UE & 1 & - & I & + & + & Mucoide, lisa, AT \\
\hline 19 & $\mathrm{O}$ & 7 & - & $\mathrm{F}$ & + & + & Mucoide, lisa, incolora \\
\hline R28 & $\mathbf{R}$ & 28 & - & I & + & + & Lisa, aplanada, NT \\
\hline $\mathrm{R} 8$ & $\mathrm{R}$ & 8 & - & $\mathrm{F}$ & + & + & Lisa, aplanada, SP \\
\hline ULC8 & UE & 8 & - & D & + & + & Lisa, aplanada, NT \\
\hline ULC19 & UE & 19 & - & D & + & + & Mucoide, lisa, AT \\
\hline ULC28 & UE & 28 & - & $\mathrm{F}$ & + & + & Mucoide, lisa, SP \\
\hline AGA19 & A & 19 & - & $\mathrm{F}$ & + & + & Mucoide, grisáceo \\
\hline ULC7 & UE & 7 & - & I & + & + & Lisa, aplanada, SP \\
\hline ULC20 & UE & 20 & - & PD & + & + & Lisa, aplanada, NT \\
\hline HIG7 & $\mathrm{H}$ & 7 & - & I & + & + & Lisa, aplanada, SP \\
\hline FOR19 & For & 19 & - & PD & + & + & Lisa, aplanada, AT \\
\hline
\end{tabular}

(*) H: hígado; R: riñón; UE: úlcera externa; O: globo ocular; A: agallas; For: forúnculo.

$\left.{ }^{* *}\right)$ I: inmóvil; PD: pobremente deslizante; D: deslizante; F: movimiento flagelar.

$\left.{ }^{* * *}\right)$ SP: sin pigmento aparente; AT: amarillo tenue; NT: naranja tenue; PN: pigmento naranja.

En el medio Agar Anacker \& Ordal (AOA), F. psychrophilus produce colonias convexas, brillantes, con borde entero o difusos que no se adhieren al agar y que producen un pigmento amarillo no difusible del tipo flexirrubina. Nuestras cepas no presentaron una pigmentación evidente, salvo algunas que mostraron pigmentos amarillo y naranja tenues (Tabla 1).

Respecto al metabolismo oxido-fermantivo de las 29 cepas, la mayoría (13 de 29) degradó glucosa en presencia de oxígeno; sin embargo algunas cepas mostraron un comportamiento típico de fermentador (6 de 29); sin embargo, en ningún caso produjeron gas. Solo en dos casos se observó presencia de $\mathrm{H}_{2} \mathrm{~S}$. Las cepas presuntivas de flavobacterias se mostraron no oxidantes o excepcionalmente oxidantes de glucosa (Tabla 2). El crecimiento frente a diferentes valores de temperatura indica que crecen favorablemente a $20^{\circ} \mathrm{C}$, aunque algunas crecieron muy bien entre 5 y $30^{\circ} \mathrm{C}$. Todas las cepas crecieron sin y con $\mathrm{NaCl}$ (hasta $1,0 \%$ ). Holt (1994), Ekman (2003), y Cipriano \& Holt (2005) señalan que Flavobacterium psychrophilum crece muy bien en cultivos de 3 a 6 días a $15-20{ }^{\circ} \mathrm{C}$ de incubación, así como también en su hábitat natural, en ríos y lagos con temperaturas que oscilan entre 10 y $18^{\circ} \mathrm{C}$. Otras características fenotípicas consideradas en el estudio de las 29 cepas mostraron resultados variables frente a diferentes polímeros; sin embargo, la capacidad degradativa de las flavobacterias sobre la gelatina, caseína, Tween 80 , DNA y lecitina fue bastante homogénea (Tabla 3). Por otro lado, la mayoría de las cepas resultaron con escasa o nula actividad sobre el almidón, quitina, alginato y carboximetilcelulosa. Estos resultados sobre flavobacterias concuerdan con los de Cipriano $\&$ Holt (2005).

En relación al examen microbiológico, podemos afirmar que las células bacterianas del agente patógeno a pesar de presentar variantes morfológicas, en líneas generales guarda estrecha relación con las bacterias filamentosas del grupo CytophagaFlexibacter descritas por Lorenzen et al. (1991), Wakabayashi et al. (1991) y Lorenzen et al. (1997). Respecto a la motilidad Bernardet \& Kerouault (1989) determinaron a Flavobacterium psychrophilum como un género "pobremente deslizante" lo cual concuerda con la mayoría de las cepas aisladas en este trabajo, en especial con 9 cepas provenientes de ulceraciones y órganos internos (Tabla 3).

Asimismo, otros patógenos oportunitas aislados en el presente trabajo fueron Aeromonas (6/29) y Pseudomonas (6/29) (Tabla 3).

Las características de cultivo y pruebas bioquímicas nos permiten identificar al agente patógeno como miembros del grupo Cytophaga-Flexibacter-Flavobacterium. Flavobacterium psychrophilum también ha sido encontrado en el mucus, riñón, bazo, fluido ovárico y fluido seminal de peces sexualmente maduros y en la superficie de los huevos (Holt et al. 1993; Lorenzen 1994; 
Tabla 2. Características bioquímicas y fisiológicas de 29 cepas de bacterias aisladas de alevines enfermos de Oncorhynchus mykiss "trucha arco iris", Centro Piscícola El Ingenio, Huancayo, 2003. En negrita: cepas identificadas como Flavobacterium psychrophilum.

\begin{tabular}{|c|c|c|c|c|c|c|c|c|c|c|c|}
\hline \multirow[b]{2}{*}{ Cepa } & \multirow[b]{2}{*}{ Reducción de $\mathrm{NO}_{3}$ a $\mathrm{NO}_{2}$} & \multirow[b]{2}{*}{ Prueba de $O / F$} & \multirow[b]{2}{*}{$\mathrm{H}_{2} \mathrm{~S}$} & \multirow[b]{2}{*}{ Gas } & \multirow[b]{2}{*}{ Indol } & \multicolumn{3}{|c|}{$\mathrm{T}^{\mathrm{o}}$ crecimiento $\left({ }^{\circ} \mathrm{C}\right)$} & \multicolumn{3}{|c|}{ Tolerancia a $\mathrm{NaCl}(\%)$} \\
\hline & & & & & & 5 & 20 & 30 & 0 & 0,5 & 1,0 \\
\hline 1 & + & $\mathrm{F}$ & - & - & + & + & + & - & + & + & + \\
\hline 2 & + & $\mathrm{F}$ & - & - & + & - & + & + & + & + & + \\
\hline 3 & + & $\mathrm{F}$ & - & - & + & + & + & + & + & + & + \\
\hline 4 & + & $\mathrm{O}$ & - & - & + & - & + & + & + & + & + \\
\hline 5 & + & $\mathrm{O}$ & - & - & - & - & + & - & + & + & + \\
\hline 6 & + & $\mathrm{O}$ & - & - & - & - & + & - & + & + & + \\
\hline 7 & + & $\mathrm{O}$ & - & - & + & - & + & + & + & + & + \\
\hline 8 & + & - & - & - & + & + & + & - & + & + & + \\
\hline 9 & - & - & + & - & - & - & + & - & + & + & + \\
\hline 10 & - & - & + & - & - & - & + & - & + & + & + \\
\hline 11 & - & - & - & - & + & - & + & - & + & + & + \\
\hline 12 & + & $\mathrm{O}$ & - & - & - & - & + & + & + & + & + \\
\hline 13 & - & - & - & - & - & - & + & - & + & + & + \\
\hline 14 & - & $\mathrm{O}$ & - & - & - & - & + & - & + & + & + \\
\hline 15 & + & $\mathrm{F}$ & - & - & + & - & + & - & + & + & + \\
\hline 16 & - & - & - & - & - & - & + & + & + & + & + \\
\hline 17 & + & $\mathrm{O}$ & - & - & + & - & + & - & + & + & + \\
\hline 18 & - & O & - & - & - & - & + & - & + & + & + \\
\hline 19 & + & $\mathrm{F}$ & - & - & + & - & + & + & + & + & + \\
\hline R28 & - & O & - & - & - & - & + & + & + & + & + \\
\hline $\mathrm{R} 8$ & + & $\mathrm{F}$ & - & - & + & - & + & + & + & + & + \\
\hline ULC8 & - & - & - & - & - & - & + & + & + & + & + \\
\hline ULC19 & - & - & - & - & + & - & + & - & + & + & + \\
\hline ULC28 & + & $\mathrm{O}$ & - & - & + & - & + & + & + & + & + \\
\hline AGA19 & - & $\mathrm{F}$ & - & - & - & + & + & + & + & + & + \\
\hline ULC7 & + & $\mathrm{O}$ & - & - & + & - & + & - & + & + & + \\
\hline ULC20 & - & $\mathbf{O}$ & - & - & + & - & + & - & + & + & + \\
\hline HIG7 & + & $\mathrm{O}$ & - & - & + & - & + & - & + & + & + \\
\hline FOR19 & + & - & - & - & - & + & + & - & + & + & + \\
\hline
\end{tabular}

F: fermentador de glucosa; O: oxidador de glucosa; - : sin reacción o alcalinidad del medio

Obach et al. 1995). Esto sugiere que la bacteria podría ser transmitida verticalmente e indica el riesgo de su introducción en otras áreas geográficas debido al transporte incontrolado de huevos y alevines infectados (Holt et al., 1993; Obach et al., 1995). Si bien todos estos datos sugieren que tanto los peces como el medio ambiente pueden constituir un reservorio del microorganismo, no se han realizado estudios para esclarecer este aspecto.

La manifestación de la enfermedad del agua fría así como el curso de la epizootia están profundamente influenciados por la temperatura del agua. Generalmente la enfermedad se manifiesta cuando del agua oscila entre 4 y $10{ }^{\circ} \mathrm{C}$ y sigue su curso hasta que la temperatura del agua alcanza los $13^{\circ} \mathrm{C}$. En este sentido, la temperatura del agua del lugar de estudio fue en promedio 10 ${ }^{\circ} \mathrm{C}$, el cual es ideal para el desarrollo del patógeno. Aunque temperaturas superiores normalmente conducen a la desaparición de la enfermedad (Holt et al., 1989) se han descrito epizootias a temperaturas del orden de $16^{\circ} \mathrm{C}(\mathrm{Obach}$ et al. 1995). A temperaturas superiores a $15^{\circ} \mathrm{C}$ la mortalidad declina progresivamente hasta llegar cerca del $0 \%$ a $23^{\circ} \mathrm{C}$.

Además de la temperatura del agua existen otros factores ambientales desencadenantes de las epizootias como la irradiación solar directa a los alevines muy jóvenes, el estrés, la superpoblación y otros factores inherentes al pez (talla, estado inmunológico) que pueden condicionar la aparición y/o desarrollo de la enfermedad (Obach et al. 1995). A todo ello, se debe agregar la virulencia de la cepa bacteriana (Lorenzen et al.
1991; Bertolini et al. 1994; Bustos et al. 1995). Respecto a las condiciones ambientales del lugar de muestreo (El Ingenio) es necesario precisar que dicha epizootia ocurrió justamente en los meses de mayor irradiación solar (junio, julio y agosto) y en estanques desprotegidos, disminuyendo considerablemente la mortandad cuando se recurrió a la protección solar. Hasta el momento se han realizado pocos estudios con el fin de esclarecer los mecanismos de virulencia de F. psychrophilum. Las proteasas extracelulares podrían contribuir a la patogenicidad, ya que se ha demostrado que producen diferentes enzimas proteolíticas capaces de degradar gelatina, caseína, tirosina, elastina, fibrinógeno, colágeno y extracto de músculo que podrían causar lesiones en los tejidos o incrementar la capacidad invasiva de las cepas (Dalsgaard 1993). Al respecto, las cepas aisladas en el presente estudio mostraron una actividad extracelular de gran consideración principalmente gelatinasa y lecitinasa (Tabla 3). No se han investigado otros potenciales factores de virulencia relacionados con la superficie celular como son la adherencia e invasividad o la capacidad para sobrevivir en el interior de las células fagocíticas.

Por otra parte, los brotes mas graves de la enfermedad del agua fría se producen en alevines que aún no han reabsorbido el saco vitelino y por lo tanto no se alimentan mediante pienso (Nematollahi et al. 2003), lo que imposibilita su medicación a través de la dieta. La vacunación en esta etapa es inefectiva o confiere una protección limitada (Obach \& Baudin-Laurencin 
Tabla 3. Producción de Enzimas Extracelulares (EEC) de 29 cepas de bacterias aisladas de alevines enfermos de Oncorhynchus mykiss "trucha arco iris", Centro Piscícola El Ingenio, Huancayo, 2003. En negrita: cepas identificadas como Flavobacterium psychrophilum.

Producción cualitativa de enzimas extracelulares (EEC)

\begin{tabular}{|c|c|c|c|c|c|c|c|c|c|c|}
\hline Cepa & GEL & CAS & QUIT & $\mathrm{AM}$ & LEC & TWsa & ALG & CMC & DNA & Identificación \\
\hline 1 & ++++ & ++ & - & $(+)$ & ++ & ++ & - & - & - & Aeromonas sp. \\
\hline 2 & ++++ & ++ & - & - & ++ & +++ & - & - & - & Aeromonas sp. \\
\hline 3 & +++ & ++ & - & $(+)$ & ++ & +++ & - & - & - & Aeromonas sp. \\
\hline 4 & +++ & + & - & - & ++ & +++ & - & - & ++ & Pseudomonas sp. \\
\hline 5 & ++++ & - & - & - & +++ & +++ & - & - & +++ & Pseudomonas sp. \\
\hline 6 & +++ & ++ & - & + & ++ & ++ & - & - & ++ & Pseudomonas sp. \\
\hline 7 & ++++ & + & - & - & ++ & +++ & - & - & +++ & Pseudomonas sp. \\
\hline 8 & ++++ & ++ & - & - & $(+)$ & +++ & - & - & ++ & F. psychrophilum \\
\hline 9 & +++ & - & - & - & ++ & ++ & - & - & - & NI \\
\hline 10 & +++ & +++ & - & $(+)$ & $(+)$ & +++ & - & - & - & F. psychrophilum \\
\hline 11 & ++++ & ++ & - & - & - & +++ & - & - & - & F. psychrophilum \\
\hline 12 & +++ & +++ & - & - & + & ++ & - & - & +++ & Pseudomonas sp. \\
\hline 13 & +++ & + & - & - & + & - & - & - & +++ & F. psychrophilum \\
\hline 14 & ++ & - & - & + & - & - & - & - & +++ & NI \\
\hline 15 & +++ & ++ & - & + & ++ & +++ & - & - & +++ & Aeromonas sp \\
\hline 16 & ++ & - & - & ++ & +++ & ++ & - & - & - & Flavobacteriun sp. \\
\hline 17 & ++ & ++ & - & + & +++ & +++ & - & - & +++ & Flexibacter sp. \\
\hline 18 & + & ++ & - & - & $(+)$ & ++++ & - & - & +++ & F. psychrophilum \\
\hline 19 & ++ & ++ & - & - & +++ & +++ & - & - & +++ & Aeromonas sp. \\
\hline R28 & + & ++ & - & - & - & ++ & - & - & - & F. psychrophilum \\
\hline $\mathrm{R} 8$ & + & ++ & - & - & ++ & ++ & - & - & - & Aeromonas sp. \\
\hline ULC8 & +++ & +++ & - & $(+)$ & - & +++ & - & - & +++ & F. psychrophilum \\
\hline ULC19 & +++ & + & - & - & $(+)$ & ++ & - & - & +++ & F. psychrophilum \\
\hline ULC28 & +++ & + & - & $(+)$ & ++ & +++ & - & - & +++ & Pseudomonas sp. \\
\hline AGA19 & ++++ & ++ & - & + & ++ & - & - & - & - & NI \\
\hline ULC7 & +++ & + & - & $(+)$ & ++ & ++ & - & - & +++ & Flavobacterium sp \\
\hline ULC20 & +++ & ++ & - & - & $(+)$ & ++ & - & - & +++ & F. psychrophilum \\
\hline HIG7 & +++ & ++ & - & - & ++ & ++ & - & - & ++ & Flavobacterium sp \\
\hline FOR19 & - & - & - & - & - & - & - & - & - & Flexibacter $\mathrm{sp}$ \\
\hline
\end{tabular}

EEC: GEL (gelatinasa); CAS (caseínasa); QUIT (quitinasa); AM (amilasa); LEC (lecitinasa); TWsa (tween esterasa); ALG (alginasa); CMC (caboximetilcelulasa); DNA (DNAsa). Halos de actividad enzimática (mm de diámetro): (+): reacción débil; +: <5 mm; ++: 5-15 mm; +++: 16-30 mm; ++++: >30 mm; -: sin actividad.

En negrita: cepas identificadas como Flavobacterium psychrophilum; NI: cepa no identificada.

1991; Lorenzen 1994). Por otra parte, la posible diversidad serológica de las cepas de F. psychrophilum debe ser tomada en cuenta en el desarrollo de una vacuna.

Actualmente, los análisis serológicos tipo aglutinación son de gran utilidad para el diagnóstico confirmativo de la enfermedad del agua fría, así como ensayos de anticuerpos fluorescentes (Holt 1994), pero se ha determinado la existencia de reacciones cruzadas con otras bacterias filamentosas como $F$. columnaris u otros grupos bacterianos (Faruk et al. 2002; Mata et al. 2002). Actualmente para muestras de campo existen varios métodos de identificación todos basados en técnicas moleculares como PCR y RFLP (Baliarda et al. 2002; Nilsson \& Strom 2002; del Cerro et al. 2002a y b).

\section{Sensibilidad frente a diversos antimicrobianos}

La sensibilidad de las 29 cepas de bacterias aisladas de alevines enfermos fue variable frente a diferentes antibióticos, sin embargo, todas mostraron sensibilidad antibiótica propia de bacterias Gram negativas. Resultaron altamente sensibles frente a Gentamicina $(100 \%)$, Ceftazidina $(100 \%)$, oxitetraciclina $(93,1 \%)$, Norfloxacina $(93,1 \%)$, furazolidona $(89,6 \%)$, Ciprofloxacina $(75,8 \%)$ y Cefoxitina $(75,8 \%)$ (Tabla 4). Asimismo, resultaron altamente resistentes frente a sulfatrimetoprim $(100 \%)$, penicilina $(96,5 \%)$, clindamicina $(89,6 \%)$ y bacitracina $(86,2 \%)$.
El cloranfenicol fue el antibiótico más usado para el tratamiento de la enfermedad del agua fría, sin embargo, desde su prohibición la oxitetraciclina bajo diferentes prescripciones terapéuticas es la terapia mas eficaz en la actualidad (Bruun et al., 2003). Generalmente, la enfermedad del agua fría es controlada

Tabla 4. Sensibilidad in vitro de 29 cepas de bacterias aisladas de alevines enfermos de Oncorhynchus mykiss "trucha arco iris", frente a diferentes antimicrobianos. Centro Piscícola El Ingenio, Huancayo, 2003.

\begin{tabular}{|c|c|c|c|c|c|c|}
\hline \multirow{3}{*}{ Antimicrobiano ( $\mu \mathrm{g})$} & \multicolumn{6}{|c|}{ Sensibilidad } \\
\hline & \multicolumn{2}{|c|}{ Sensible } & \multicolumn{2}{|c|}{ Intermemedia } & \multicolumn{2}{|c|}{ Resistente } \\
\hline & $\mathrm{N}^{\mathrm{o}}$ & $\%$ & $\mathrm{~N}^{\circ}$ & $\%$ & $\mathrm{~N}^{\circ}$ & $\%$ \\
\hline Ac. Nalidíxico (30) & 14 & 48,2 & 9 & 31,0 & 6 & 20,6 \\
\hline Bacitracina (10) & 1 & 3,4 & 3 & 10,3 & 25 & 86,2 \\
\hline Ciprofloxacina (5) & 22 & 75,8 & 7 & 24,1 & - & - \\
\hline Norfloxacina (10) & 27 & 93,1 & - & - & 2 & 6,8 \\
\hline Ampicilina (10) & 3 & 10,3 & 3 & 10,3 & 23 & 79,3 \\
\hline Cefoxitina (30) & 22 & 75,8 & 1 & 3,4 & 6 & 20,6 \\
\hline Clindamicina (2) & 2 & 6,8 & 1 & 3,4 & 26 & 89,6 \\
\hline Penicilina (10U) & - & - & 1 & 3,4 & 28 & 96,5 \\
\hline Furazolidona (100) & 26 & 89,6 & 3 & 10,3 & - & - \\
\hline Gentamicina (10) & 29 & 100 & - & - & - & - \\
\hline Ceftazidina (30) & 29 & 100 & - & - & - & - \\
\hline Oxitetraciclina (30) & 27 & 93,1 & 2 & 6,8 & - & - \\
\hline Sulfatrimetoprim (25) & - & - & - & - & 29 & 100 \\
\hline
\end{tabular}


por medios terapéuticos, aunque el constante uso de éstos ha provocado la aparición de cepas resistentes (Holt et al., 1993; Lorenzen, 1994; Obach et al., 1995).

\section{Agradecimientos}

Los autores agradecen a los directivos y trabajadores del Centro Piscícola El Ingenio - Huancayo, en especial al Blgo. Jorge Véliz Caballero Director Regional del Ministerio de la Producción - PRODUCE - Región Centro por su disponibilidad de promover trabajos de investigación en el área de acuicultura.

\section{Literatura citada}

Amita, K., M. Hoshino, T. Honma, \& H. Wakabayashi. 2000. An investigation on the distribution of Flavobacterium psychrophilum in the Umikawa River. Fish Pathology 35: 193-197.

Amos, K. 1985. Procedures for the detection and identification of certain fish pathogens. $3^{\text {a }}$ Edit. Fish Health Section, American Fishery Society, Corvallis, Oregon. pp. 57-58.

Anaker, R.L. \& E.J. Ordal. 1959. Studies on the myxobacterium Chondrococcus columnaris. 1. Serological typing. J. Bacteriol. 78: 25-32

Austin, B. \& D.A. Austin, 1993. Bacterial fish pathogens: Disease in farmed and wild fish. $2^{\text {a }}$ Edit. Ellis Horwood Ltd., Chichester, UK. pp. 228-252.

Baliarda, D., D. Faure \& M.C.Urdaci. 2002. Development and application of a nested PCR to monitor brood stock salmonid ovarian fluid and spleen for detection of the fish pathogen Flavobacteriun psychrophilum. Journal of Applied Microbiology 92: 510-516.

Bernardet, J.F., F. Baudin-Laurencin \& G. Tixeran. 1988. First identification of Cytophaga psychrophila in France. Bull. Eur. Ass. Fish Pathol. 8: 104-105.

Bernardet, J.F. \& B. Kerouault. 1989. Phenotypic and genomic studies of Cytophaga psychrophila isolated from diseased rainbow trout (Oncorhynchus mykiss) in France. Appl. Env. Microbiol. 55: 1796-1800.

Bernardet, J.F., P. Seger, M. Vancanneyt, F. Berthe, K. Kersters \& P. Vandamme. 1996. Cutting a Gordian Knot: Emended Classification and Description of the Genus Flavobacterium, Emended Description of the Family Flavobacteriaceae, and proposal of Flavobacterium hydatis nom.nov. (Basonim, Cytophaga aquatilis Strohl and Tait 1978). International Journal of Systematic Bacteriology 46, 128-148.

Bertolini, J.M., H. Wakabayashi, V.G.Watral, M.J.Whipple \& J.S. Rojovec, 1994. Electrophoretic detection of proteasas from selected strains of Flexibacter psychrophilus and assessment of their variability. Journal of Aquatic Animal Health. 6: 224-233.

Borg, AF. 1960. Studies on myxobacteria associated with diseases in salmonid fishes. American Association for the Advancement of Science, Wildlife Disease 8: 1-85, Washington DC, USA.

Bruun, M.S., I.Madsen \& I. Dalsgaard. 2003. Efficacy of oxytetracycline treatment in rainbow trout experimentally infected with Flavobacterium psychrophilum strains having different in vitro antibiotic susceptibilities. Aquaculture, 215: 11-20.

Bustos, P.A., J. Calbuyahue, J. Montaña, B. Opazo, P. Entrala \& R. Solervicens. 1995. First isolation of Flexibacter psychrophilus, as a causative agent of rainbow trout fry syndrome (RTFS), producing rainbow trout mortality in Chile. Bull. Eur. Ass. Fish Pathol. 15: 162-164.

Cerro del, A., M.C., Mendoza \& J.A. Guijarro. 2002ª Usefulness of a Taqman-based polymerase chain reaction assay for the detection of the fish pathogen Flavobacterium psychropilum. J. Appl. Microbiol. 93: 149-156.
Cerro del, A., I. Marquez \& A. Guijarro. 2002b. simultaneous detection of Aeromonas salmonicida, Flavobacterium psychrophilum and Yersinia ruckeri, three major fish pathogens by multiplex PCR. Appl. Environ. Microbiol. 68: $5177-5180$

Cipriano, R.C.; W.B. Schill; J.D. Teska \& L.A. Ford. 1996. Epizootiological Study of Bacterial Cold-Water Disease in Pacific Salmon and Further Characterization of the Etiologic Agent, Flexibacter psychrophila. Journal of Aquatic Animal Health. 8: 28-36

Cipriano, R.C. \& R.A. Holt. 2005. Flavobacterium psychrophilum, cause of Bacterial Cold-Water Disease and Rainbow Trout Fry Syndrome. Fish Disease Leaflet No. 86. United States Dept. of the Interior. U.S. Geological Service, National Fish Health Research Laboratory, Kearneysville, WV.

Cuéllar, L. 1984. Acuicultura e ictiopatología. Actas de Academia de Ciencias Veterinarias de Madrid. Vol. II. 205-221.

Crump, E.M., M.B. Perry, S.C. Clouthier \& W.W. Kay. 2001. Antigenic characterization of the fish pathogen Flavobacterium psychrophilum. Appl. Environ. Microbiol. 67 (2): $750-759$

Dalsgaard, I. \& V. Horlyck. 1990. Cytophaga psychrophila infection in raibow trout in Denmark (abstract). Proc. Conference on Bacterial Disease on Fish. P.37

Dalsgaard, I. 1993. Virulence mechanisms in Cytophaga psychrophila and other Cytophaga-like bacteria pathogenic for fish. Ann. Rev. Fish Dis. 3: 127-144.

Davis, H.S. 1946. Care and diseases of trout. US Dept. of Interior Research Report $N^{\circ} 12$, US Government Printing Office, Washington, DC.USA.

Ekman, E. 2003. Natural and experimental infections with Flavobacterium psychropilum in salmonid fish. Doctoral thesis. Swedish University of Agricultural Sciences Uppsala.

Faruk, M.A., R.E. Campbell, K.D. Thompson, R.E. Rangdale \& R.H. Richards. 2002. Characterization of Flavobacterium psychropilum the causative agent of rainbow trout fry syndrome (RTFS) using rabbit antiserum. Bull. Eur. Assoc. Fish Pathol. 22: 354-365.

FAO. 2000. The state of world fisheries and aquaculture (SOFIA). http://www.fao.org/sof/sofia/index_en.htm. ISBN 92-5104492-9

Holt, R.A., A. Amandi, J.S.Rohovec, \& J.L.Fryer. 1989. Relation of water temperature to bacterial cold-water disease in coho salmon, Chinook salmon and rainbow trout. J. Aquat. Animal Health. 1: 94-101.

Holt, R.A., J.S. Rohovec \& J.L. Fryer. 1993. Bacterial cold-water disease. In "bacterial disease of fish" (Inglis, V., Roberts, RJ \& Bromage, NR. Eds.). Blackwell Scientific Publications, Oxford, UK. Pp.3-22.

Holt, R.A. 1994. Cold water Disease. Pp. IV: 1-4, in: Suggested procedures for the detection and identification of certain finfish and shellfish pathogens, $4^{\mathrm{a}}$ edition, version 1 , Thocsen, JC., ed. Fish Health Section. American Fisheries Society. Bethesda, Maryland.

Lorenzen, E., I. Dalsgaard, J. From, E.M. Hansen, V. Horlyck, et al. 1991. Preliminary investigations of fry mortality syndrome in rainbow trout. Bull. Eur. Ass. Fish Pathol. 11: 77-79.

Lorenzen, E. 1994. Studies on Flexibacter psychrophilus in relation to Rainbow Trout Fry Syndrome (RTFS). Ph. D. Thesis. National Veterinary Laboratory, Arhus and Royal Veterinary and Agricultural University, Copenhagen.

Lorenzen, E., I.Dalsgaard \& JF. Bernardet. 1997. Characterization of isolates of Flavobacterium psychrophilum associated with coldwater disease or rainbow trout fry syndrome I: phenotypic and genomic studies. Diseases of Aquatic Organisms. 31: 197-208. 
Madetoja, J., M.L. Hanninen, V. Hirvela-Koski, I. Dalsgaard, \& T. Wiklund. 2001. Phenotypic and genotypic characterization of Flavobacterium psychrophilum from Finnish fish farm. Journal of Fish Disease. 24: 469-479.

Madetoja, J \& T. Wiklund. 2002. Detection of the fish pathogen Flavobacterium psychrophilum in water from fish farms. Systematic and applied Microbiology. 25: 259-266.

Mata, M., A. Skarmeta \& Y. Santos. 2002. A proposed serotyping system for Flavobacterium psychrophilum. Lettr. Appl. Microbiol. 35: 166-170.

Nematollahi, A., A. Decostere, F. Pasmans, R. Ducatelle, \& F. Haesebrouck. 2003. Adhesion of high and low virulent Flavobacterium psychrophilum strains to isolated gill aches of rainbow trout Oncorhynchus mykiss. Diseases of Aquatic Organisms. 55: 101-107.

National Committee for Clinical Laboratory Standards. 1991. Performance standards for antimicrobial susceptibility tests, $4^{\text {th }}$ ed. Aproved standard.

Obach, A. \& F. Baudin-Laurencin, 1991. Vaccination of rainbow trout Oncorhynchus mykiss against the visceral form of coldwater disease. Dis. Aquat. Org. 12: 13-15.

Obach, A., R. Rangdale, \& A. Roem. 1995. Rainbow Trout Fry Syndrome. Aetiology, epidemiology, treatment of Flexibacter psychrophilus infection. ARC UPDATE. 3.

Ostland, V.P., P.J. Byrne, J.S. Lumnsden, D.D. MacPhee, J.A. Decksen, et al. 1999. Atypical bacterial gill disease: a new form of bacterial gill disease affecting intensively reared salmonids. J. Fish Dis. 22: 351-358.

Padrós, F. y M. D. Furones. 2002. Patología bacteriana en piscicultura. Temas de Actualidad SEM No 34: 13-21.

Rangdale, R.E., R.H. Richards \& D.J. Aldeman. 1996. Isolation of Cytophaga psychrophila, causal agent of rainbow trout fry syndrome (RTFS) from reproductive fluids and egg surface of rainbow trout (Oncorhynchus mykiss). Bulletin of the European Association Of fish pathologists. 16: 63-67.
Rangdale, R.E. 1999. Rainbow trout fry syndrome. Bull. Eur. Assoc. Fish Pathol. 19:295

Santos, Y., P.J.Huntly, A.Turnbull, \& T.S. Hastings. 1992. Isolation of Cytophaga psychrophila (Flexibacter psychrophilus) in association with rainbow trout mortality in United Kingdom. Bull. Eur. Ass. Fish Pathol. 12:209-210.

Sarti, M., G. Giorgetti, \& A. Manfrin. 1992. Method for the rapid diagnosis of visceral myxobacteriosis in reared trout in Italy. Bull. Eur. Ass. Fish Pathol. 12: 53.

Shotts, E.B. \& C.E. Starliper. 1999. Flavobacterial Disease: Columnaris Disease, Cold-water Disease and Bacterial Gill Disease. In: P.K.T. Woo and D.W. Bruno, eds. Fish Diseases and Disorders, Vol. 3 CABI publishing. Pp. 559-576.

Skarmeta, A.M. 1996. Caracterización bioquímica, serológica y molecular del patógeno de peces Flexibacter psychrophilus. Tesis Doctoral, Universidad de Santiago de Compostela, España.

Toranzo, A.E. \& J.L. Barja. 1993. Fry mortality syndrome (FMS) in Spain. Isolation of the causative bacterium Flexibacter psychrophilus. Bull. Eur. Ass. Fish Pathol. 13: 30-32.

Wakabayashi, H., M. Horiuchi, T. Bunya, \& T. Hoshiai. 1991. Outbreaks of cold-water disease in coho salmon in Japan. Fish Pathol. 26: 211-212.

Weis, J. 1987. A cold water disease in rainbow trout. Ucber das Vorkommen eimer Kaltwasserkranheir bei Regenbogenforellen, Salmo gairdneri. Tierdzslicher Umschau. 42: 575-577.

Wiklund, T., K. Kaas, I. Lonnstron, \& I. Dalsgaard. 1994. Isolation of Cytophaga psychrophila (Flexibacter psychrophilus) from wild and farm rainbow trout (Oncorhynchus mykiss) in Finland. Bull. Eurp. Assoc. Fish Path. 14: 44-46 